\title{
Kinetic Analyses of Desulfurization of Dibenzothiophene by Rhodococcus erythropolis in Batch and Fed-Batch Cultures
}

\author{
PING WANG† AND STEVEN KRAWIEC** \\ Department of Biological Sciences, Lehigh University, Bethlehem, Pennsylvania 18015-4732
}

Received 9 June 1995/Accepted 17 February 1996

\begin{abstract}
The DbtS $^{+}$phenotype (which confers the ability to oxidize selectively the sulfur atom of dibenzothiophene [DBT] or dibenzothiophene sulfone [DBTO $\left.{ }_{2}\right]$ ) of Rhodococcus erythropolis N1-36 was quantitatively characterized in batch and fed-batch cultures. In flask cultures, production of the desulfurization product, monohydroxybiphenyl (OH-BP), was maximal at $\mathrm{pH}$ 6.0, while specific productivity $\left(\mathrm{OH}-\mathrm{BP}\right.$ cell $\left.^{-1}\right)$ was maximal at $\mathrm{pH}$ 5.5. Quantitative measurements in fermentors (in both batch and fed-batch modes) demonstrated that DBTO$_{2}$ as the sole sulfur source yielded a greater amount of product than did DBT. Specifically, $100 \mu M$ DBT maximally yielded $\approx 40 \mu \mathrm{M}$ OH-BP, while $100 \mu \mathrm{M} \mathrm{DBTO}_{2}$ yielded $\approx 60 \mu \mathrm{M}$ OH-BP. Neither maintaining the pH at 6.0 nor adding an additional carbon source increased the yield of OH-BP. The presence of $\mathrm{SO}_{4}{ }^{2-}$ in growth media repressed expression of desulfurization activity, but $\mathrm{SO}_{4}{ }^{2-}$ added to suspensions of cells grown in DBT or $\mathrm{DBTO}_{2}$ did not inhibit desulfurization activity.
\end{abstract}

The combustion of unprocessed fossil fuels releases noxious sulfoxides. To avoid production of such pollutants, sulfur must be removed from fossil fuels before, during, or after combustion. Physical and chemical means of sulfur removal are costly. Biological desulfurization has the prospect of being both inexpensive and metabolically specific (6-8).

Microbial desulfurization is often studied with dibenzothiophene (DBT), a compound composed of two benzene moieties and a thiophene. DBT models an especially recalcitrant form of organic sulfur in fossil fuels. Organisms with a $\mathrm{DbtS}^{+}$phenotype selectively remove the sulfur atom from DBT or dibenzothiophene sulfone $\left(\mathrm{DBTO}_{2}\right)(7,12)$. Two features of this phenotype are noteworthy: (i) the atom which might be released as a pollutant (a sulfoxide) is fully oxidized to a watersoluble sulfate, and (ii) the carbon frame of the substrate is only slightly oxidized. The former feature means that the potentially noxious atom is released in a tractable form; the latter feature means that the calorific value of the substrate is only slightly reduced. These features suggest that microbial desulfurization of fossil fuels is an attractive prospect $(7,8)$. For that possibility to be realized, the rate, extent, and control of desulfurization must first be described.

Several desulfurization pathways have been identified; the intermediates and final products vary with the phase of growth and with the bacterial species mediating the desulfurization (1, $4,5,9,10,12)$. Also, knowledge about the desulfurization phenotype was, until recently, qualitative; three recent reports provided some quantitative data $(4,5,11)$. The kinetic data reported here confirm and extend previous results and thereby securely establish desulfurization of selected thiophenes by Rhodococcus erythropolis as a quantitative phenomenon. Optimal conditions for growth and for production of the desulfurization product are presented. Notably, the consumption of substrate as well as the appearance and stability of the product in batch and fed-batch cultures is correlated with (i) the avail-

\footnotetext{
* Corresponding author. Mailing address: Department of Biological Sciences, 111 Lehigh University, Bethlehem, PA 18015-4732. Electronic mail address: sk08@lehigh.edu.

† Present address: Borland Laboratory, The Pennsylvania State University, University Park, PA 16802.
}

ability of the carbon source, (ii) the abundance and identity of the sulfur source, and (iii) the phase of growth.

\section{MATERIALS AND METHODS}

Strains. Three R. erythropolis strains (N1-36, N1-43, and Q1a-22) were studied (15).

Media. The sulfur-free basal medium was a modification of medium 21c of Guirard and Snell (2): all sulfate salts were replaced by the corresponding chloride salts, the addition of vitamins was omitted, and $3 \mathrm{~g}$ of glucose liter $^{-1}$ was added. The concentrations of sulfur sources in the DBT, $\mathrm{DBTO}_{2}$, benzothiophene (BT), and $\mathrm{MgSO}_{4}$ media were, respectively, $0.1 \mathrm{mM} \mathrm{DBT}, 0.1 \mathrm{mM}$ DBTO $_{2}, 0.05 \mathrm{mM} \mathrm{BT}$, and $0.2 \mathrm{mM} \mathrm{MgSO}_{4}$. The organic sulfur sources were added as a powder of fine crystals, enmeshed on nylon filters (8-mm nylon filter discs were dipped in $5 \%$ ethyl ether solutions of $\mathrm{DBT}$ or $\mathrm{DBTO}_{2}$; the solvent was allowed to evaporate), or dissolved as $200 \times$ stock ethanol solutions; the last of these methods gave the most reliable result. $\mathrm{MgSO}_{4}$ was added as an aqueous solution; to control for the effect of ethanol, the same amount of ethanol $(0.5 \%)$ was sometimes included in the $\mathrm{MgSO}_{4}$ medium.

$\mathrm{MgSO}_{4}$ medium was used in experiments in which the effect of ethanol was measured. Medium with no carbon source served as a control. The experimenta media contained additions of 0.1 to $3.0 \%$ ethanol, $0.3 \%$ glucose, or $0.3 \%$ glucose plus $0.1,0.5$, or $1.0 \%$ ethanol.

$\mathrm{DBTO}_{2}$ media (buffered with $50 \mathrm{mM}$ phosphate to pHs 5.0, 5.5, 6.0, 6.5, 7.0, 7.5 , and 8.0) were used to determine the effect of $\mathrm{pH}$ on growth and desulfurization activities

All shake flask cultures were incubated at room temperature $\left(\leq 25^{\circ} \mathrm{C}\right)$ on a platform shaker operated at $200 \mathrm{rpm}$.

Inocula. To determine the effect of ethanol, $2 \%$ inocula were prepared from 2-day-old cultures of N1-36 maintained in $\mathrm{MgSO}_{4}$ medium with no ethanol. To determine the effect of $\mathrm{pH}, 5 \%$ inocula were prepared from 1-day-old cultures of N1-36 growing with $\mathrm{MgSO}_{4}$ as a sulfur source and $0.1 \%$ ethanol as a carbon source. For fermentors, $5 \%$ inocula were prepared from exponentially growing $\mathrm{N} 1-36$ cultures (in DBT or $\mathrm{DBTO}_{2}$ medium) with an optical density (OD) at 660 $\mathrm{nm}$ equal to approximately 1.0. For all inocula, the cells were harvested, washed, and suspended in saline before being added to fresh medium.

Cell concentrations. Cell concentrations in samples of cultures were estimated by measuring the ODs at $660 \mathrm{~nm}$. Linear relationships between culture OD and cell dry weight and between OD and CFU were obtained in the OD range of 0.1 to 0.9 ; specifically, dry weight $\left(\right.$ grams $\cdot$ liter $\left.^{-1}\right)=0.38 \mathrm{OD}-0.0048$ and CFU $\left(\right.$ milliliter $\left.^{-1} \cdot 10^{8}\right)=8.88 \mathrm{OD}-0.11$. A Milton Roy Company Spectronic 601 spectrophotometer was used to measure the ODs.

Quantitative analysis of reactants. A YSI model 23A glucose analyzer (Yellow Spring Instrument Co., Inc.) was used to measure glucose concentrations in batch and fed-batch culture supernatants. A Shimadzu UV-visible recording spectrophotometer (model UV-160) was used to measure absorption spectra. A high-performance liquid chromatograph equipped with a reversed-phase Brownlee column (Spheri-5, RP-18; $5 \mu \mathrm{m}, 100$ by $4.6 \mathrm{~mm}$ ) with $50 \%$ acetonitrile as the mobile phase (flow rate, $1.6 \mathrm{ml} \cdot \mathrm{min}^{-1}$ ) and an ISCO $\mathrm{V}^{4}$ absorbance detector (set at $254 \mathrm{~nm}$ ) was used for the quantitative assay of DBT, $\mathrm{DBTO}_{2}$, monohydroxybiphenyl (OH-BP), and biphenyl (BP)

Desulfurization activity. For estimation of desulfurization activities, $1 \mathrm{ml}$ of 
culture suspension was mixed with $4 \mathrm{ml}$ of phosphate buffer ( $\mathrm{pH} 6.0$ ) containing $0.1 \mathrm{mM}$ DBT or $\mathrm{DBTO}_{2}$. At time zero and subsequent times, $0.5-\mathrm{ml}$ samples were mixed with $0.5 \mathrm{ml}$ of $\mathrm{CH}_{3} \mathrm{CN}$ to stop the reaction; the mixtures were filtered through $0.2-\mu \mathrm{m}$-pore-size nylon filters. Concentrations of OH-BP were then measured. One unit of activity is defined as $1 \mu \mathrm{mol}$ of $\mathrm{OH}-\mathrm{BP}$ produced in $1 \mathrm{~min}$.

Growth in bioreactor. The standard conditions for kinetic analyses in bioreactors were as follows: temperature, $30^{\circ} \mathrm{C}$; agitation, $300 \mathrm{rpm}$; and aeration, 1.5 $\mathrm{vol} / \mathrm{vol} / \mathrm{min}$. The $\mathrm{pH}$ was initially 6.0 and in some instances was maintained at 6.0 by injection of $\mathrm{NaOH}(2 \%, \mathrm{wt} / \mathrm{vol})$ or $3 \% \mathrm{HCl}$ as needed. For fed-batch cultures, glucose solutions were injected into the reactors (to a final concentration of 3.0 $\mathrm{g} \cdot$ liter $\left.^{-1}\right)$ in late exponential phase. Antifoam $(0.02 \%$, vol $/ \mathrm{vol})$ was included in the media for all of the batch and fed-batch cultures.

The studies of batch cultures were performed in a BioFlo C30 reactor (New Brunswick Scientific, Inc.) with a working volume of $355 \mathrm{ml}$ or in a computercontrolled BioFlo III reactor (New Brunswick Scientific, Inc.) with a working volume of 1.5 liters. An Ingold $\mathrm{pH}$ probe, a Fisher Accumet $\mathrm{pH}$ meter (model 805MP), a Galvanic dissolved oxygen probe, and an ABEC dissolved oxygen meter (model DDA100) were used to monitor and control the broth pHs and dissolved oxygen concentrations of cultures on-line during fermentations.

\section{RESULTS}

HPLC analysis. The high-performance liquid chromatography (HPLC) analytic method used in this study detects DBT, dibenzothiophene sulfoxide, $\mathrm{DBTO}_{2}, \mathrm{BP}, o, o^{\prime}-\mathrm{BP}$, and $\mathrm{OH}-\mathrm{BP}$ at retention times of approximately $15.4,1.48,2.45,11.2,1.92$, and $3.40 \mathrm{~min}$, respectively (13). When DBT was used as the sole sulfur source for N1-36, small amounts of dibenzothiophene sulfoxide were detected in the culture medium between 10 and $35 \mathrm{~h}$ after inoculation; no $\mathrm{DBTO}_{2}$ or dibenzothiophene sulfonate was detected (13). For cultures with either DBT or $\mathrm{DBTO}_{2}$ as the sole sulfur source, OH-BP was the principal desulfurization product, an observation which conforms to the $4 \mathrm{~S}$ pathway $(3,7)$.

Effect of pH. The growth of N1-36 and production of OH-BP were measured at $\mathrm{pHs}$ ranging from 5.0 to 8.0; the growth of N1-43 and Q1a-22 and the appearance of product were measured at pHs of 6.0 to 8.0. For N1-43 and Q1a-22, the rates and extents of growth were largely equivalent at $\mathrm{pHs}$ 6.0, 6.5, 7.0, and 8.0; for N1-36, the extent of growth was reduced at $\mathrm{pHs}$ of $\leq 6.0$. For all strains, OH-BP production began in early exponential phase. The extents of $\mathrm{OH}-\mathrm{BP}$ production for both $\mathrm{N} 1-36$ and $\mathrm{N} 1-43$ were greatest at $\mathrm{pH} 6.0$ (data not shown) (13). The final concentrations of $\mathrm{OH}-\mathrm{BP}$ produced at $\mathrm{pH} 6.0$ from $0.1 \mathrm{mM} \mathrm{DBTO}$ by $\mathrm{Q} 1 \mathrm{a}-22, \mathrm{~N} 1-36$, and N1-43 were, respectively, approximately 42,75 , and $76 \mu \mathrm{M}$.

The cell concentrations, concentrations of $\mathrm{OH}-\mathrm{BP}$, and specific desulfurization activities of 115 -h-old batch cultures of N1-36 at different pHs indicated that (i) N1-36 has the greatest extent of growth at $\mathrm{pH} 6.5$, (ii) optimal desulfurization (for the culture) occurs at $\mathrm{pH}$ 6.0, and (iii) optimal specific desulfurization activity (per cell) occurs at pH 5.5 (data not shown) (13). However, at pH 5.5 (or lower), a very limited amount of cell growth occurs, and, correspondingly, the total desulfurization activity is much lower than at $\mathrm{pH} 6.0$. Because $\mathrm{pH} 6.0$ is an effective $\mathrm{pH}$ for desulfurization, this value was used in all subsequent experiments.

Effect of ethanol. DBT or $\mathrm{DBTO}_{2}$ was introduced into sulfur-free media (i) as a powder, (ii) enmeshed in nylon filters, or (iii) from $200 \times$ ethanol stock solutions. For controls, $\mathrm{MgSO}_{4}$ was introduced into shake flask cultures in aqueous solutions or on nylon filters with or without a volume of ethanol equivalent to the amounts used to deliver DBT or $\mathrm{DBTO}_{2}$ to the experimental cultures. Measurements of growth showed that the presence of ethanol allowed N1-36 to respond to $\mathrm{SO}_{4}{ }^{2-}$ more rapidly than when $\mathrm{SO}_{4}{ }^{2-}$ was introduced in aqueous solution or on a nylon filter (data not shown). Likewise, DBT or $\mathrm{DBTO}_{2}$ as a sulfur source supported more rapid growth of N1-36 if the DBT or $\mathrm{DBTO}_{2}$ was introduced in ethanol rather than as a powder or enmeshed in nylon filters (data not shown) (13).
An extension of this analysis demonstrated that ethanol is an effective carbon source for N1-36 at low concentrations and is an inhibitor at higher concentrations. Growth of N1-36 with no carbon source was compared with growth supported by glucose, ethanol, or combinations of glucose and ethanol. The concentration of glucose was $0.3 \%$; the concentrations of ethanol were $0.1,1.0,1.5,2.0,2.5$, and $3.0 \%$; and the concentrations of mixed carbon sources were $0.3 \%$ glucose and $0.1 \%$ ethanol or $0.3 \%$ glucose and $1.0 \%$ ethanol. The cultures containing 0.1 or $1.0 \%$ ethanol exhibited a shorter lag time and more rapid exponential growth than cultures grown with glucose alone. However, the presence of ethanol in media at concentrations higher than $1.0 \%$ produced progressively decreased exponential growth rates and slightly reduced extents of growth (data not shown) (13).

Effect of desulfurization substrates: DBT, DBTO ${ }_{2}$, and BT. Neither DBT nor $\mathrm{DBTO}_{2}$ inhibited cell growth at concentrations up to $200 \mu \mathrm{M}$ (Fig. 1). Furthermore, growth of N1-36 in

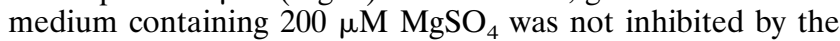
addition of DBT or DBTO 2 to concentrations of 50,100 , and $200 \mu \mathrm{M}$.

BT did support growth of strain N1-36 when present as the sole sulfur source, although the extent of growth with BT alone was much lower than that with either DBT or $\mathrm{DBTO}_{2}$. A chromogenic assay (15) indicated that phenol or some phenolic compound(s) was produced in both $\mathrm{BT}$ and $\mathrm{BT}-\mathrm{MgSO}_{4}$ cultures. Cells grown on BT showed no ability to desulfurize DBT or $\mathrm{DBTO}_{2}$. The absence of induction of the $\mathrm{DbtS}^{+}$phenotype by BT and the absence of inhibition of product formation by $\mathrm{SO}_{4}{ }^{2-}$ indicate that the process by which BT is used to satisfy the sulfur requirement of N1-36 is different from the process used with DBT or $\mathrm{DBTO}_{2}$ (see below).

Effect of desulfurization products: $\mathrm{OH}-\mathrm{BP}$ and $\mathrm{SO}_{4}{ }^{2-}$. $\mathrm{OH}-\mathrm{BP}$ at 50 or $100 \mu \mathrm{M}$ produced a slight inhibition of growth (Fig. 2). Specifically, at 0, 50, and $100 \mu \mathrm{M} \mathrm{OH-BP,} \mathrm{the} \mathrm{specific}$ growth rates of exponential-phase cells were, respectively, $0.190,0.187$, and $0.170 \mathrm{~h}^{-1}$. The extents of growth were also lowered.

$\mathrm{OH}-\mathrm{BP}$ is not produced from DBT or $\mathrm{DBTO}_{2}$ in cultures containing $\mathrm{MgSO}_{4}$. Furthermore, N1-36, N1-43, or Q1a-22 grown in the presence of $\mathrm{MgSO}_{4}$ shows no desulfurization activity. By contrast, the desulfurization activities of N1-36 grown for 2 days in the presence of $\mathrm{DBTO}_{2}$ and in the absence of $\mathrm{MgSO}_{4}$ are unaffected by the inclusion of $\mathrm{MgSO}_{4}$ in the assay reactants. These observations indicate that the $\mathrm{DbtS}^{+}$ phenotype is inducible by DBT or $\mathrm{DBTO}_{2}$ and that $\mathrm{SO}_{4}{ }^{2-}$ represses $\mathrm{DbtS}^{+}$expression but does not inhibit the desulfurization enzyme activities (13).

Growth in bioreactors. Batch and glucose-fed-batch cultures of N1-36 having either DBT or $\mathrm{DBTO}_{2}$ as the sole sulfur source were used to establish the kinetics of both growth and desulfurization. The concentrations of DBT or $\mathrm{DBTO}_{2}, \mathrm{OH}-$ $\mathrm{BP}$, and glucose as well as the pHs and ODs (at $660 \mathrm{~nm}$ ) were monitored.

The specific exponential growth rate $(\mu)$ of batch cultures with DBT as the sulfur source was $0.153 \mathrm{~h}^{-1}$, while the corresponding rate with $\mathrm{DBTO}_{2}$ as the sulfur source was $0.180 \mathrm{~h}^{-1}$. (A definitive determination of the maximum specific growth rate of $\mathrm{N1}-36$ in a $\mathrm{DBTO}_{2}$-limited continuous culture has been calculated [14].) As shown in Fig. 3 and 4, the stationary phase of growth was rapidly achieved; specifically, with a 5\% inoculum, stationary phase typically occurred after approximately 40 $\mathrm{h}$ of growth. In all instances, high yields of cells $\left(3 \times 10^{9}\right.$ to 1 $\times 10^{10}$ cells $\cdot \mathrm{ml}^{-1}$ ) were achieved. Concomitant with growth, the concentration of DBT or $\mathrm{DBTO}_{2}$ rapidly diminished. The extent of DBT or $\mathrm{DBTO}_{2}$ utilization was high; the substrate 


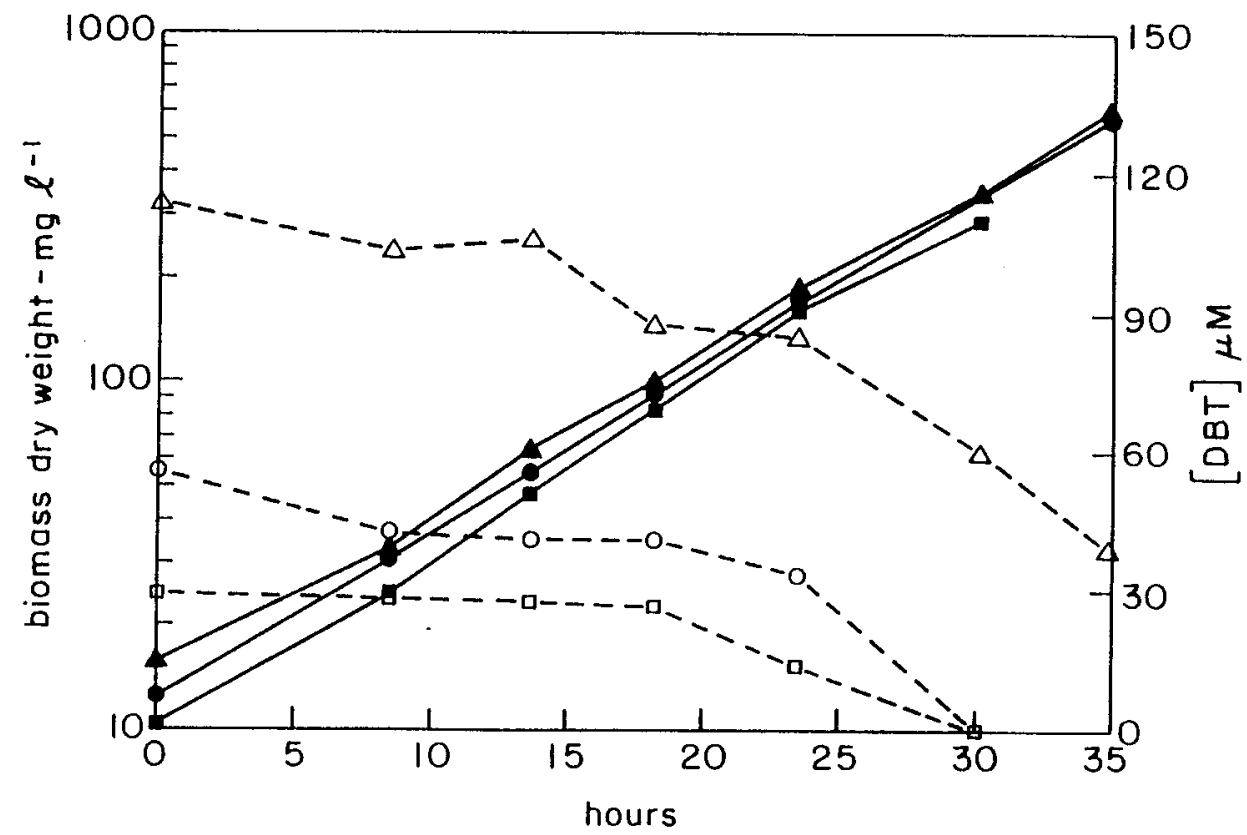

FIG. 1. Effect of DBT concentration on growth of N1-36. Closed symbols, biomass; open symbols, [DBT]; triangles, initial DBT concentration of $200 \mu \mathrm{M}$; circles, initial DBT concentration of $100 \mu \mathrm{M}$; squares, initial DBT concentration of $50 \mu \mathrm{M}$.

was reduced to very low concentrations $(\leq 5 \mu \mathrm{M})$ or undetectable concentrations before late exponential phase. OH-BP production lagged behind cell growth; the production of $\mathrm{OH}-\mathrm{BP}$ occurred sooner and was greater in extent when $\mathrm{DBTO}_{2}$ was the substrate (compared with DBT). The rate of OH-BP production was $1.77 \mu \mathrm{M} \cdot \mathrm{h}^{-1}$ with DBT as the substrate and $2.44 \mu \mathrm{M} \cdot \mathrm{h}^{-1}$ with $\mathrm{DBTO}_{2}$ as the substrate. The decrease in $\mathrm{pH}$ correlated with the appearance of OH-BP. The yield of $\mathrm{OH}-\mathrm{BP}$ peaked at a time approximately equivalent to that of the transition from late exponential phase to stationary phase; at this time, $\mathrm{OH}-\mathrm{BP}$ concentrations were approximately $40 \mu \mathrm{M}$ for DBT cultures and approximately $60 \mu \mathrm{M}$ for $\mathrm{DBTO}_{2}$ cultures. During growth of the cultures without $\mathrm{pH}$ control, the $\mathrm{pH}$ of the media dropped. The extent of the $\mathrm{pH}$ change was greater in $\mathrm{DBTO}_{2}$ cultures than when DBT served as the sulfur source. The decline in $\mathrm{pH}$ did not prevent production of $\mathrm{OH}-\mathrm{BP}$ or affect the presence of $\mathrm{OH}-\mathrm{BP}$.

After the highest concentrations of the desulfurization prod-

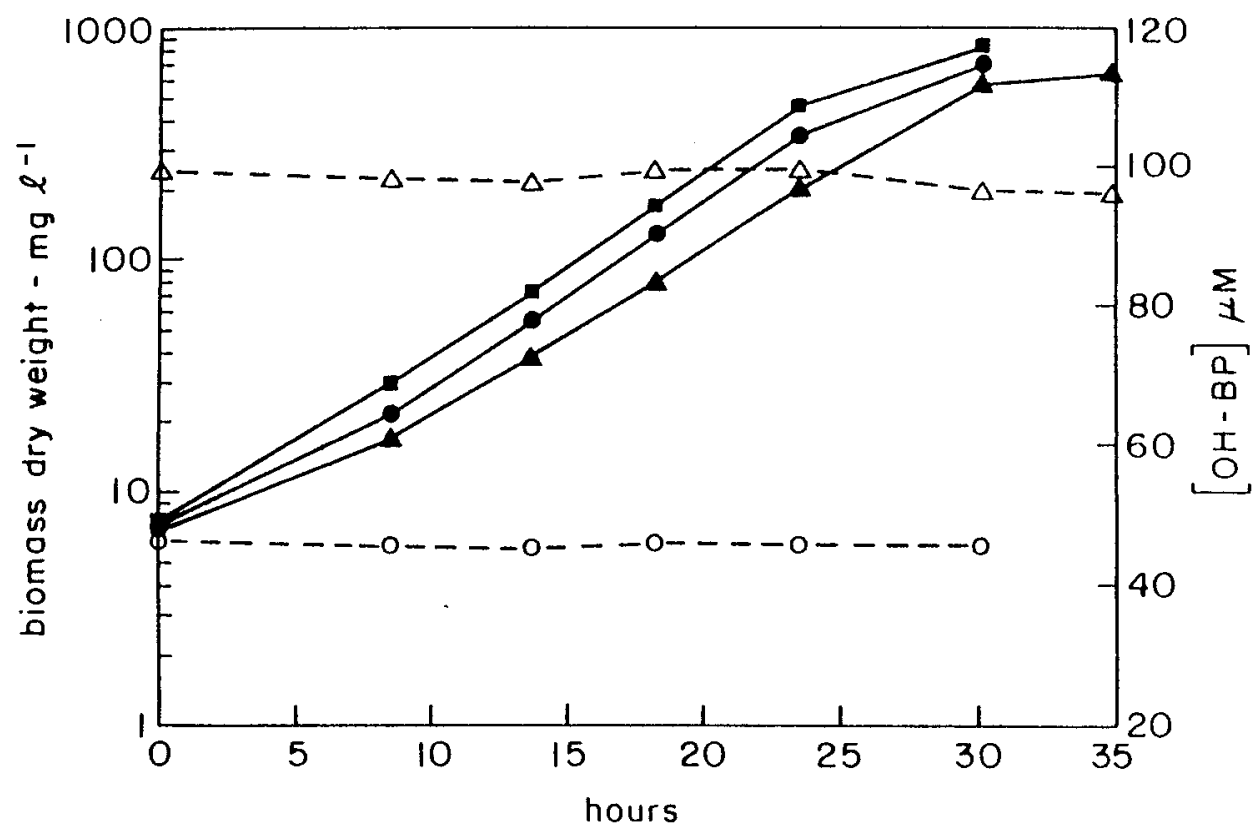

FIG. 2. Effect of OH-BP concentration on growth of N1-36. Closed symbols, biomass (squares, no addition of OH-BP to the medium; circles, addition of $50 \mu \mathrm{M}$ $\mathrm{OH}-\mathrm{BP}$; triangles, addition of $100 \mu \mathrm{M}$ OH-BP). Open symbols, [OH-BP] (triangles, addition of $100 \mu \mathrm{M} \mathrm{OH}-\mathrm{BP}$ to the medium; circles, addition of 50 $\mu \mathrm{M}$ OH-BP). The growth medium was sulfur-free medium plus $20 \mu \mathrm{M} \mathrm{MgSO}_{4}$ and $1 \%$ ethanol. 


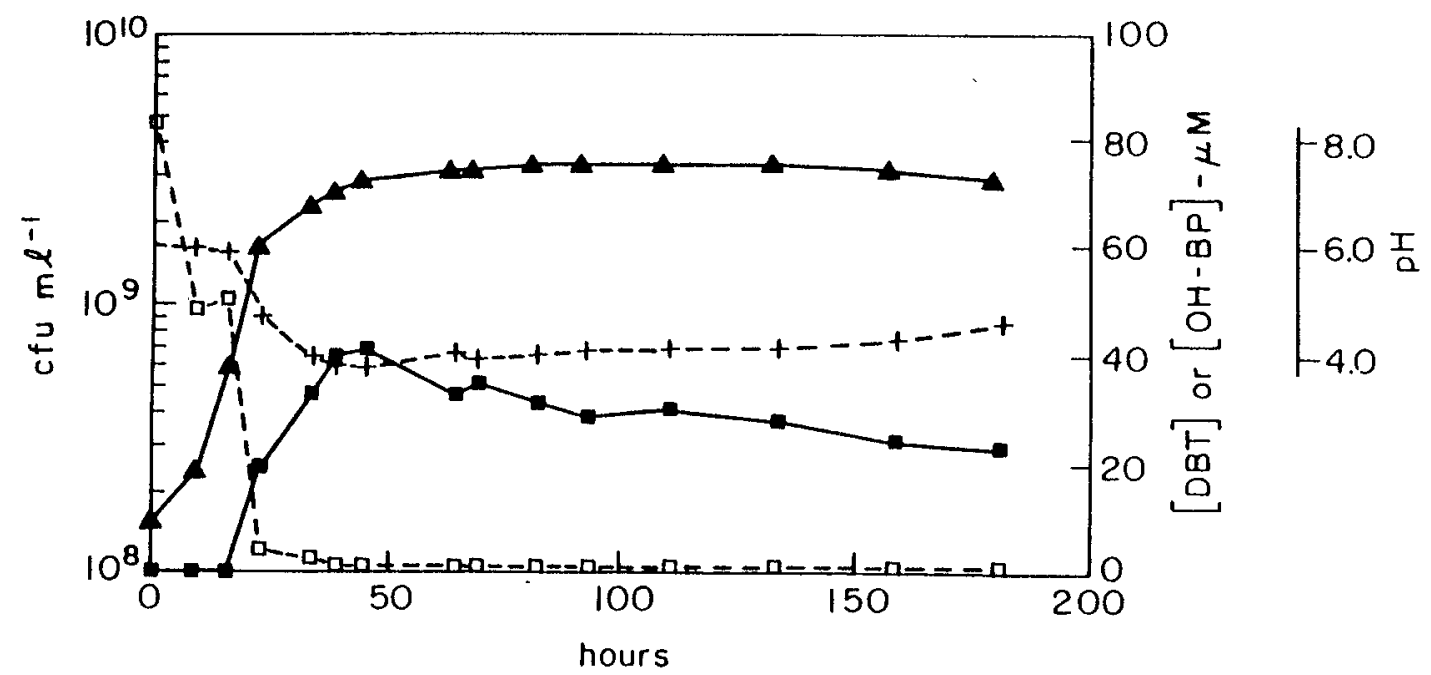

FIG. 3. Batch culture of N1-36 with DBT as the sole sulfur source. Open squares, [DBT]; triangles, $\mathrm{CFU} \cdot$ milliliter $^{-1}$; closed squares, [OH-BP]; crosses, pH.

uct, OH-BP, were achieved, the concentrations decreased to approximately 70 to $75 \%$ of the maximum yield. The possibility that the OH-BP was used as a carbon source after glucose levels became low was tested by adding glucose during cultivation (Fig. 5 and 6). Glucose was added to determine if a replenished supply would offset the decline in OH-BP. Comparisons of results for batch and fed-batch cultures show that such an addition did not affect the decline in the OH-BP level. Also, effects from changes in $\mathrm{pH}$ were eliminated by using an automatic $\mathrm{pH}$ control. In such fed-batch cultures, the growth of cells again correlated with the disappearance of substrate; as with batch cultures, DBTO $_{2}$ was consumed more rapidly than DBT. The appearance of OH-BP lagged behind the disappearance of the substrate. The rate of glucose utilization was linear and was greater with $\mathrm{DBTO}_{2}\left(-27.7 \mathrm{mg} \cdot\right.$ liter $\left.^{-1} \cdot \mathrm{h}^{-1}\right)$ than with DBT $\left(-18.4 \mathrm{mg} \cdot \operatorname{liter}^{-1} \cdot \mathrm{h}^{-1}\right)$. Neither the presence of glucose nor the control of $\mathrm{pH}$ affected the abundance of the product; likewise, neither affected the decline in the concentration of the product between 40 and $200 \mathrm{~h}$.

The concentrations of OH-BP in both inoculated and uninoculated media decreased to equivalent extents after 7 days of incubation. This equivalence excludes the possibility that $\mathrm{OH}-\mathrm{BP}$ was consumed by cells as a carbon source (15).

Small amounts of BP appeared in cultures stored for 4 or 5 days at $5^{\circ} \mathrm{C}$. Prior to storage, only $\mathrm{OH}-\mathrm{BP}$ had been detected. These circumstances suggest that some of the OH-BP may be converted to $\mathrm{BP}$. Addition of $\mathrm{CH}_{3} \mathrm{CN}$ at the time samples were taken prevented the appearance of BP. Likewise, no BP appeared in uninoculated solutions stored under identical conditions. Cumulatively, these observations indicate that conversion of $\mathrm{OH}-\mathrm{BP}$ to $\mathrm{BP}$ is a biotic process. Some OH-BP may also be abiotically removed (for example, by sublimation) from the media.

\section{DISCUSSION}

In batch fermentors with glucose and ethanol as carbon sources and DBT or $\mathrm{DBTO}_{2}$ as a sulfur source, $R$. erythropolis N1-36 grows exponentially with a doubling time of approximately $4.8 \mathrm{~h}$. (The minimum doubling time determined in continuous culture is $2.95 \mathrm{~h}$ [14].) With either DBT or $\mathrm{DBTO}_{2}$ as a sulfur source, the consumption of substrate is rapid, oc-

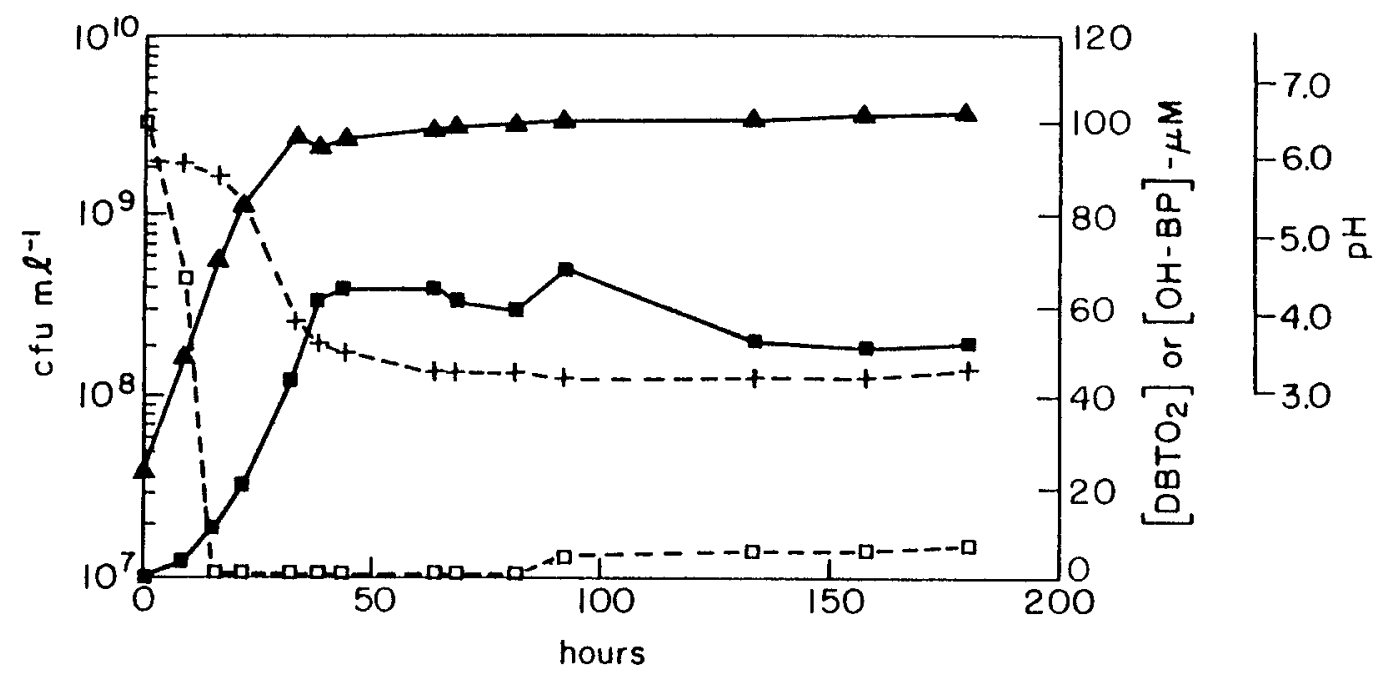

FIG. 4. Batch culture of N1-36 with $\mathrm{DBTO}_{2}$ as the sole sulfur source. Open squares, [DBTO $\mathrm{D}_{2}$; triangles, $\mathrm{CFU} \cdot$ milliliter $^{-1}$; closed squares, [OH-BP]; crosses, pH. 


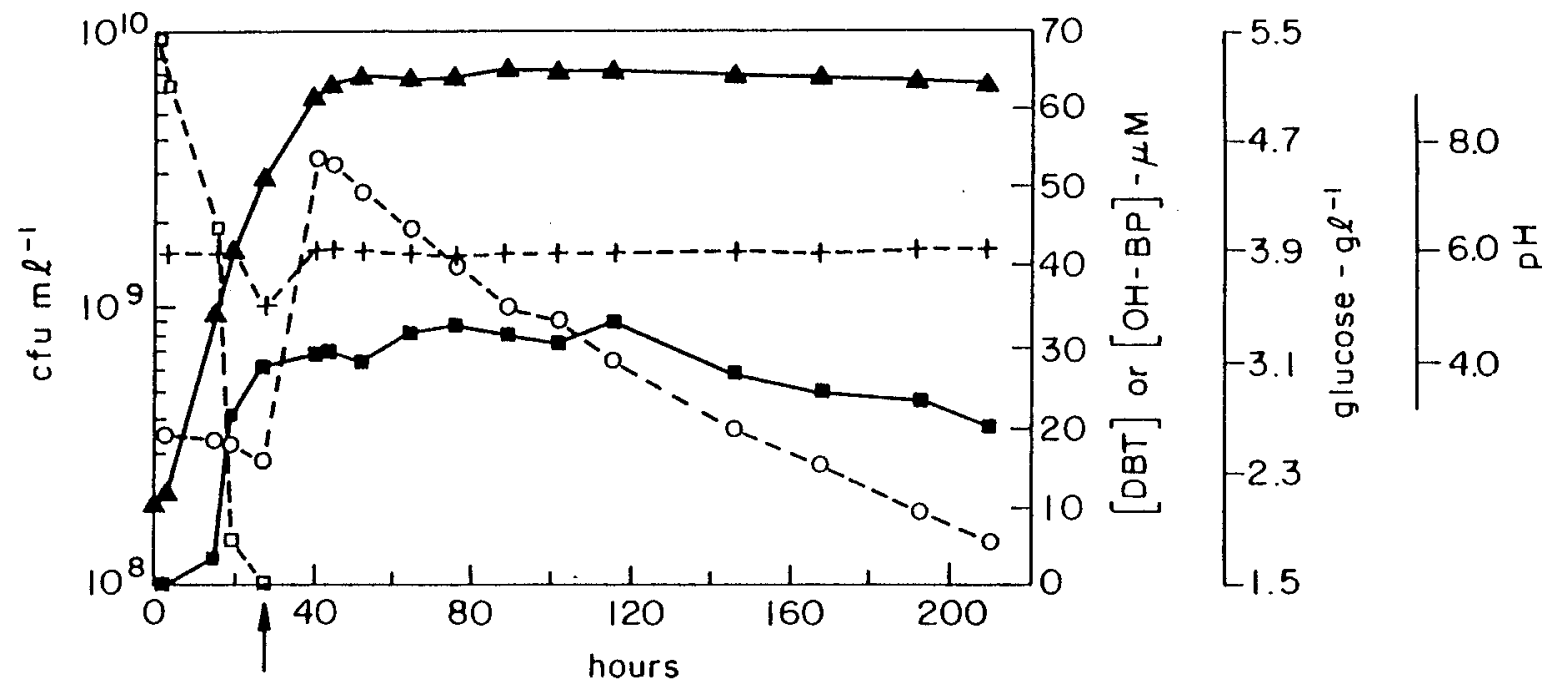

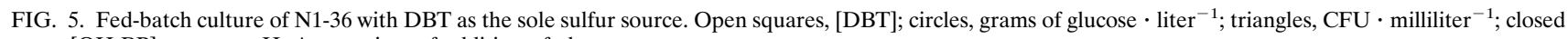
squares, [OH-BP]; crosses, pH. Arrow, time of addition of glucose.

curring, characteristically, within $20 \mathrm{~h}$. The production of $\mathrm{OH}-\mathrm{BP}$ lags behind both the disappearance of the substrate and the production of cells. With $\mathrm{DBTO}_{2}$ as the substrate, more $\mathrm{OH}-\mathrm{BP}$ is produced than when DBT is the substrate. Also with $\mathrm{DBTO}_{2}$, the change in $\mathrm{pH}$ is greater (by $1 \mathrm{U}$ ) than when DBT is the substrate. The amount of OH-BP that appears in the medium is less than the amount of DBT or $\mathrm{DBTO}_{2}$ added. Thus, the accessibility of the substrate or the stability of the product (or both) affects the yield. Some portion of the substrate may dissolve into a cell component (e.g., a membrane) or bind to a carrier or an inert surface. The amount of product decreased after approximately $40 \mathrm{~h}$. Concentrations of $\mathrm{OH}-\mathrm{BP}$ in inoculated and uninoculated media decreased to equivalent extents during 7 days of incubation (15), and OH-BP alone does not support growth (15); thus, the decline of $\mathrm{OH}-\mathrm{BP}$ does not occur because $\mathrm{OH}-\mathrm{BP}$ is consumed as a carbon source. OH-BP does inhibit growth; the organism may have an enzyme that detoxifies the inhibitor. Finally, the abundance of OH-BP may decrease because of some physical process (e.g., sublimation or partitioning). (In continuous culture, the yield coefficient, $Y_{x / s^{\prime}}$ is $9 \mathrm{mg}$ [dry weight] of cells per $\mu \mathrm{mol}$ of $\mathrm{DBTO}_{2}[14]$.)

In both batch and fed-batch cultures, the patterns of substrate consumption and product formation are similar with DBT and $\mathrm{DBTO}_{2}$ (compare Fig. 3 with Fig. 4 and Fig. 5 with Fig. 6; note also the ability to detect the initial concentration of $\mathrm{DBTO}_{2}$ added to the medium and the inability to detect the full initial concentration of DBT). A difference between the substrates is that $\mathrm{DBTO}_{2}$ has appreciable aqueous solubility whereas DBT (like many fossil fuels) has only slight solubility. The solubility of $\mathrm{DBTO}_{2}$ and the similarity of its consumption and product formation to those of DBT indicate that DBT becomes accessible to the metabolic processes of $R$. erythropolis. These results support the prospect that bacteria can effect beneficiation of (particulate) fossil fuels.

When $200 \mu \mathrm{M} \mathrm{MgSO}_{4}$ was used as a sulfur source, no desulfurization activity was seen. Evidently, the amount or

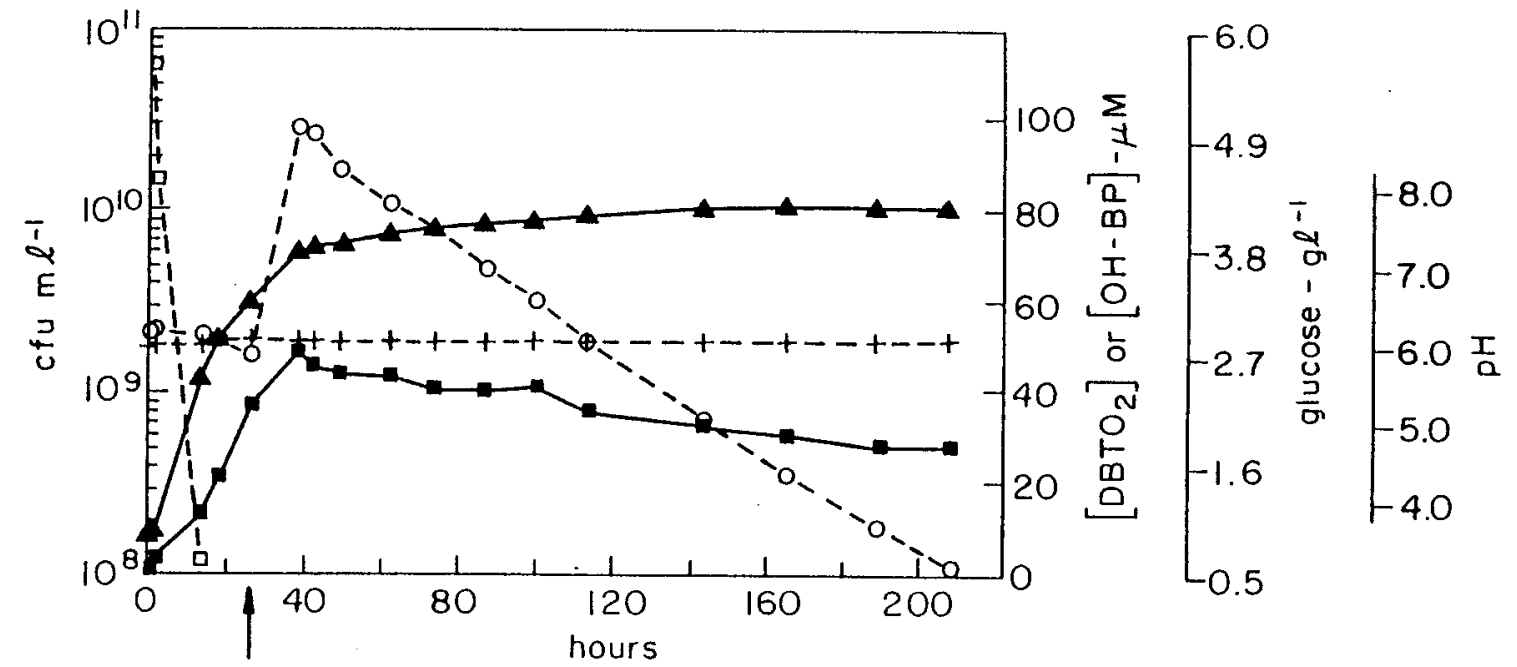

FIG. 6. Fed-batch culture of N1-36 with $\mathrm{DBTO}_{2}$ as the sole sulfur source. Open squares, [DBTO $]$; circles, grams of glucose $\cdot$ liter ${ }^{-1}$; triangles, CFU $\cdot$ milliliter ${ }^{-1}$; closed squares, [OH-BP]; crosses, $\mathrm{pH}$. Arrow, time of addition of glucose. 
form of sulfur released into the medium in batch and fed-batch cultures is insufficient to repress desulfurization.

Microbial desulfurization is important for both theoretical and practical reasons. The theoretical interest arises from the phenomenon of a heterotroph using a complex substrate to satisfy its need for sulfur but not for carbon. The practical interest is the prospect of using this metabolic specificity to desulfurize fossil fuels without adversely affecting the calorific value of the fuel. The data presented here confirm that an authentic desulfurization phenotype exits in the Rhodococcus genus; further, the rates and extents of transformations of DBT and $\mathrm{DBTO}_{2}$ are quantified.

The data confirm previous reports that some isolates of Rhodococcus spp. have the $\mathrm{DbtS}^{+}$phenotype $(4,5,11)$. The more detailed and extensive account presented here establishes the relationship between the disappearance of substrate, the growth of cells, the appearance of product, the effect of $\mathrm{pH}$ maintenance, the effect of added carbon source, and the continued presence of product. These descriptions, along with $\mu_{\max }, Y$, and Arrehnius profiles presented elsewhere (14), establish features of both the organism and the process that are important antecedents of practical applications of microbial processes.

\section{ACKNOWLEDGMENTS}

This research was supported by U.S. Department of Energy contract DE-AC22-89PC89903.

We thank Arthur E. Humphrey, who provided some of the equipment used in this work.

\section{REFERENCES}

1. Gallagher, J. R., E. S. Olson, and D. C. Stanley. 1993. Microbial desulfurization of dibenzothiophene: a sulfur-specific pathway. FEMS Microbiol. Lett. 107:31-36.
2. Guirard, B. M., and E. E. Snell. 1981. Biochemical factors in growth, p. 98. In P. Gerhardt, R. G. E. Murray, R. N. Costilow, E. W. Nester, W. A. Wood, N. R. Krieg, and G. B. Phillips (ed.), Manual of methods for general bacteriology. American Society for Microbiology, Washington, D.C.

3. Isbister, J. 1986. Biological removal of organic sulfur from coal, p. 18. In Proceedings of biological treatment of coals workshop. Sheladia Associates, Rockville, Md.

4. Izumi, Y., T. Ohshiro, H. Ogino, Y. Hine, and M. Shimao. 1994. Selective desulfurization of dibenzothiophene by Rhodococcus erythropolis D-1. Appl. Environ. Microbiol. 60:223-226.

5. Kayser, K. J., B. A. Bielaga-Jones, K. Jackowski, O. Odusan, and J. J. Kilbane III. 1993. Utilization of organosulphur compounds by axenic and mixed cultures of Rhodococcus rhodochrous IGTS8. J. Gen. Microbiol. 139: 3123-3129.

6. Kilbane, J. J., III, and K. Jackowski. 1992. Biodesulfurization of watersoluble coal-derived material by Rhodococcus rhodochrous IGTS8. Biotechnol. Bioeng. 40:1107-1114.

7. Krawiec, S. 1990. Bacterial desulfurization of thiophenes: screening techniques and some speculation regarding the biochemical and genetic bases, $p$. 103-114. In G. E. Pierce (ed.), Developments in industrial microbiology, vol. 32. Society for Industrial Microbiology, Columbus, Ohio.

8. Lipkin, R. 1994. Using bacteria to get sulfur out of oil. Sci. News 146:134.

9. Olson, E. S., D. C. Stanley, and J. R. Gallagher. 1993. Characterization of intermediates in the microbial desulfurization of dibenzothiophene. Energy Fuels 7:159-164.

10. Omari, T., L. Monna, Y. Saiki, and T. Kodama. 1992. Desulfurization of dibenzothiophene by Corynebacterium sp. strain SY1. Appl. Environ. Microbiol. 58:756-760.

11. Purdy, R. F., J. E. Lepo, and B. Ward. 1993. Biodesulfurization of organicsulfur compounds. Curr. Microbiol. 27:219-222.

12. van Afferden, M. V., S. Schact, J. Klein, and H. G. Truper. 1990. Degradation of dibenzothiophene by Brevibacterium sp. Arch. Microbiol. 153:324-328.

13. Wang, P. 1992. Ph.D. dissertation. Lehigh University, Bethlehem, Pa.

14. Wang, P., A. E. Humphrey, and S. Krawiec. Kinetic analyses of desulfurization of DBT by Rhodococcus erythropolis in continuous cultures. Submitted for publication.

15. Wang, P., and S. Krawiec. 1994. Desulfurization of dibenzothiophene to 2-hydroxybiphenyl by some newly isolated bacterial strains. Arch. Microbiol. 161:266-271. 